Article

\title{
Synthesis and Characterization of ZnO Nanowires by Thermal Oxidation of Zn Thin Films at Various Temperatures
}

\author{
Mohammad Reza Khanlary *, Vahid Vahedi and Ali Reyhani \\ Physics Department of Imam Khomeini International University, Qazvin, 34149-16818, Iran; \\ E-Mails: vahedi_vahid@yahoo.com (V.V.); reyhani@alum.sharif.edu (A.R.) \\ * Author to whom correspondence should be addressed; E-Mail: Khanlary@yahoo.com; \\ Tel. /Fax: +98-281-378-0040.
}

Received: 29 February 2012; in revised form: 16 April 2012 / Accepted: 28 April 2012 /

Published: 2 May 2012

\begin{abstract}
In this research high-quality zinc oxide ( $\mathrm{ZnO})$ nanowires have been synthesized by thermal oxidation of metallic $\mathrm{Zn}$ thin films. Metallic $\mathrm{Zn}$ films with thicknesses of $250 \mathrm{~nm}$ have been deposited on a glass substrate by the PVD technique. The deposited zinc thin films were oxidized in air at various temperatures ranging between $450{ }^{\circ} \mathrm{C}$ to $650{ }^{\circ} \mathrm{C}$. Surface morphology, structural and optical properties of the $\mathrm{ZnO}$ nanowires were examined by scanning electron microscope (SEM), X-ray diffraction (XRD), energy dispersive X-ray (EDX) and photoluminescence (PL) measurements. XRD analysis demonstrated that the $\mathrm{ZnO}$ nanowires has a wurtzite structure with orientation of (002), and the nanowires prepared at $600{ }^{\circ} \mathrm{C}$ has a better crystalline quality than samples prepared at other temperatures. SEM results indicate that by increasing the oxidation temperature, the dimensions of the $\mathrm{ZnO}$ nanowires increase. The optimum temperature for synthesizing high density, $\mathrm{ZnO}$ nanowires was determined to be $600^{\circ} \mathrm{C}$. EDX results revealed that only $\mathrm{Zn}$ and $\mathrm{O}$ are present in the samples, indicating a pure $\mathrm{ZnO}$ composition. The PL spectra of as-synthesized nanowires exhibited a strong UV emission and a relatively weak green emission.
\end{abstract}

Keywords: zinc oxide; nanowires; thermal oxidation; Zn films; crystal structure

\section{Introduction}

Zinc oxide, a wide direct band gap $(3.37 \mathrm{eV})$ semiconductor with a large exciton binding energy $(60 \mathrm{meV})$, has received much attention due to its potential applications in the optoelectronic field [1-3]. 
One-dimensional $\mathrm{ZnO}$ nanostructures such as nanowires have been extensively studied for other applications including chemical sensors [4], solar cells [5], blue and ultraviolet (UV) light-emitting diodes [6], transparent electrodes [7] and hydrogen storage [8]. Many techniques have been successfully used to synthesize $\mathrm{ZnO}$ nanowires, including sol-gel [9], pulsed laser deposition (PLD) [10], thermal evaporation [11], chemical vapor deposition (CVD) [12], etc. Another method to prepare $\mathrm{ZnO}$ nanowires, which is more or less used, is thermal oxidation of metallic $\mathrm{Zn}$ thin films. Cho et al. [13] reported the production of high quality $\mathrm{ZnO}$ films by thermal oxidation of metallic $\mathrm{Zn}$. Pure and qualified $\mathrm{ZnO}$ films have been prepared by thermal oxidation of metallic Zinc films in air [14,15]. Moreover $\mathrm{ZnO}$ nanowires with a mean diameter of $40 \mathrm{~nm}$ were synthesized by directly heating $\mathrm{Zn}$ powder in an appropriate oxygen atmosphere [16]. Similarly, Tae-Won Kim et al. have grown $\mathrm{ZnO}$ nanowires with an average diameter of $20 \mathrm{~nm}$ by thermal oxidation of predeposited-hexagonal $\mathrm{Zn}$ nanoplates on $\mathrm{a} \mathrm{CaF}_{2}$ (111) substrate [17]. Sirvatsa et al. reported the effect of oxygen flow on the growth of vertically aligned $\mathrm{ZnO}$ nanorods on $\mathrm{Si}(100)$ and sapphire (0001) substrates by using thermal evaporation of pure $\mathrm{Zn}$ powder [18]. Dai et al. also reported the formation of large-scale $\mathrm{ZnO}$ nanowires by the thermal evaporation of metallic zinc powder in the presence of water at a high temperature of about $1,000{ }^{\circ} \mathrm{C}$ [19]. However, little work has been reported on the growth of $\mathrm{ZnO}$ nanowires on glass substrates by thermal oxidation of $\mathrm{Zn}$ thin films at lower temperatures regimes $\left(<600^{\circ} \mathrm{C}\right)$.

In this paper, a very simple, cost effective, non-catalytic growth method for the synthesis of $\mathrm{ZnO}$ nanowires is presented. The $\mathrm{ZnO}$ nanowires were grown on glass substrates by the thermal oxidation in air of metallic zinc thin films at various temperatures (between 450 and $650{ }^{\circ} \mathrm{C}$ ). In addition, the growth mechanism of the nanowires is also discussed using the self-catalyzed VLS technique.

\section{Results and Discussion}

$\mathrm{X}$-ray diffraction (XRD) was employed to investigate the crystal structure of the ZnO nanowires. Figure 1 shows the XRD patterns of the samples prepared by the oxidation of $\mathrm{Zn}$ thin films at temperatures between 450 and $650{ }^{\circ} \mathrm{C}$. After the $\mathrm{Zn}$ thin films were oxidized at $450{ }^{\circ} \mathrm{C}$ and $500{ }^{\circ} \mathrm{C}$, they underwent a partial transformation from $\mathrm{Zn}$ to $\mathrm{ZnO}$. The peak at $2 \theta=34.56^{\circ}$ is related to the $\mathrm{ZnO}$ (002). Two peaks at $2 \theta=36.53^{\circ}$ and $2 \theta=77.43^{\circ}$ have been found in the XRD pattern which are related to the $\mathrm{Zn}$ and assigned as $\mathrm{Zn}(002)$ and $\mathrm{Zn}$ (004), respectively. The $\mathrm{Zn}$ peaks show that the $\mathrm{Zn}$ films have a hexagonal close packed crystal structure.

By increasing the oxidation temperature to $550{ }^{\circ} \mathrm{C}$ and higher, metallic $\mathrm{Zn}$ is completely oxidized into $\mathrm{ZnO}$. All the diffraction peaks in the patterns can be easily assigned to a $\mathrm{ZnO}$ hexagonal wurtzite structure with calculated lattice parameters of $\mathrm{a}=3.20 \AA$ and $\mathrm{c}=5.19 \AA$, which are in agreement with the reported standard values (JCPDS No. 01-089-0510). No peaks from impurities, such as Zn, are detected in the patterns, indicating the product is of high purity. The sharp diffraction peak at around $2 \theta=34.5^{\circ}$ corresponds to the reflection on (002) plane of $\mathrm{ZnO}$ and indicate that in the respective films, $\mathrm{ZnO}$ nanowires preponderantly with their c-axis orientated. Diffraction peaks for the $600{ }^{\circ} \mathrm{C}$ oxidized samples become sharper and the full width at half maximum of the (002) peak is now narrower than others, indicating the excellent crystal quality resulting from this heating process. 
Figure 1. XRD patterns of the $\mathrm{ZnO}$ nanowires prepared by the oxidation of $\mathrm{Zn}$ thin films at temperatures ranging from $450{ }^{\circ} \mathrm{C}$ to $650{ }^{\circ} \mathrm{C}$.

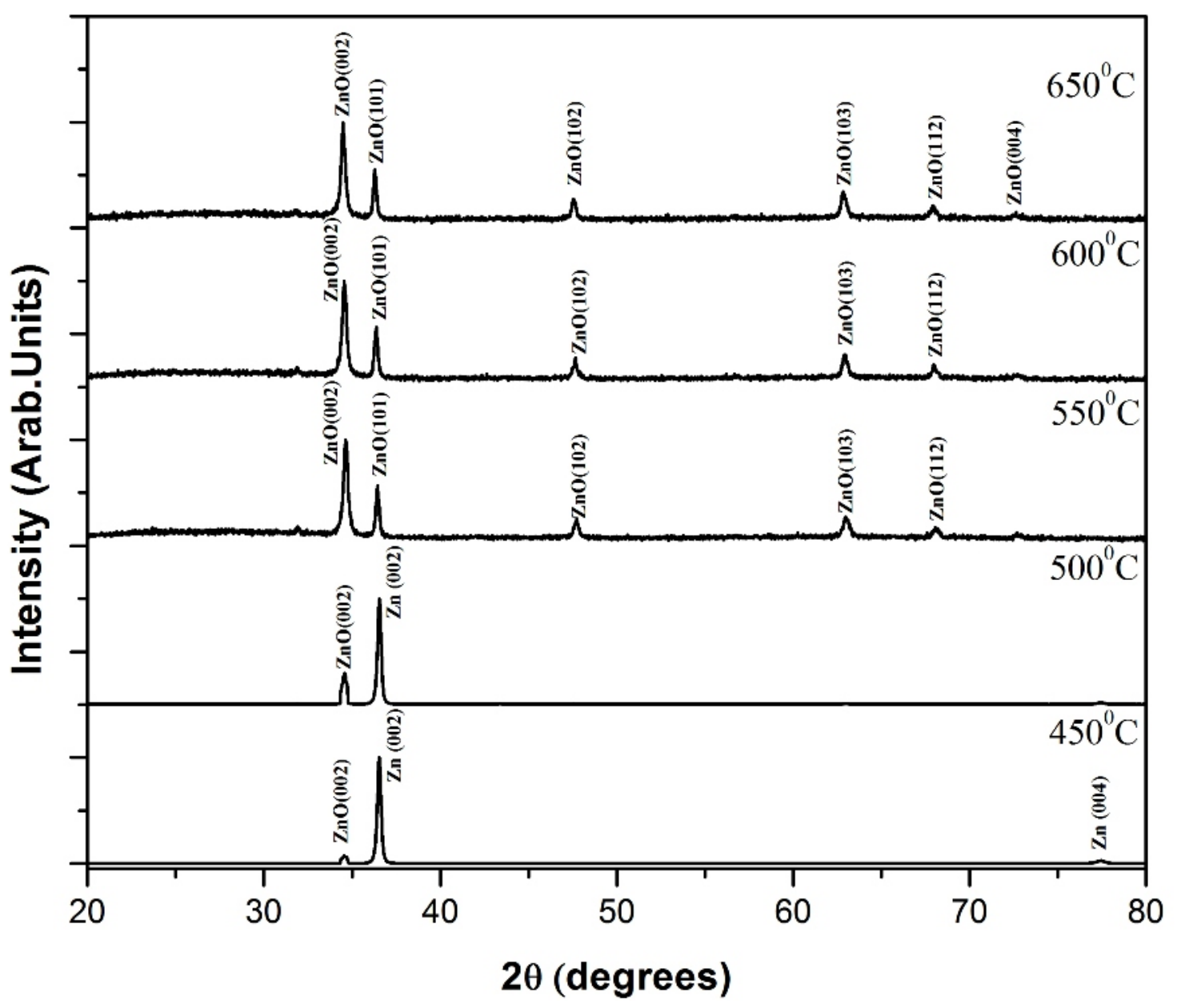

The crystallite sizes of the prepared $\mathrm{ZnO}$ nanowires were calculated using the full width at half maximum (FWHM) of the (002) peak employing Scherrer's formula [20]:

$$
d=\frac{0.9 \lambda}{\beta \cos \theta}
$$

where $\lambda, \theta$ and $\beta$ are the X-ray wavelength $(0.154 \mathrm{~nm})$, Bragg diffraction angle and FWHM, respectively. The mean grain sizes of the samples were $60 \mathrm{~nm}, 63 \mathrm{~nm}, 70 \mathrm{~nm}$ for the samples oxidized at $500{ }^{\circ} \mathrm{C}, 550{ }^{\circ} \mathrm{C}$ and $600{ }^{\circ} \mathrm{C}$, respectively, which indicates that the particle size increases with the increasing oxidation temperature. However, by further increasing the temperature to $650{ }^{\circ} \mathrm{C}$, this value decreased, as the mean grain size for the sample oxidized at $650{ }^{\circ} \mathrm{C}$ was $60 \mathrm{~nm}$. We think that the results are probably due to the deformation of the glass substrates at $650{ }^{\circ} \mathrm{C}$.

Figure 2 shows the SEM images of the $\mathrm{ZnO}$ nanowires prepared by oxidation of the $\mathrm{Zn}$ films for $1 \mathrm{~h}$ at different temperatures of 450, 500, 550, 600 and $650{ }^{\circ} \mathrm{C}$. Figure $2 \mathrm{a}$ shows the $\mathrm{ZnO}$ nanowires formed at $450{ }^{\circ} \mathrm{C}$ with a diameter of about $38 \mathrm{~nm}$ and an average length of $280 \mathrm{~nm}$. By increasing the oxidation temperature, the nanowires produced become longer. Average diameters (obtained by the Microstructure Measurement software) of the nanowires fabricated at $500{ }^{\circ} \mathrm{C}$ and $550{ }^{\circ} \mathrm{C}$ (Figure $2 \mathrm{~b}, \mathrm{c}$ ) are $52 \mathrm{~nm}$ and $72 \mathrm{~nm}$ and their lengths are $420 \mathrm{~nm}$ and $770 \mathrm{~nm}$, respectively. By increasing the oxidation temperature to $600{ }^{\circ} \mathrm{C}$, the nanowire concentration becomes higher, as shown in Figure $2 \mathrm{~d}$, 
with a measured diameter of approximately $87 \mathrm{~nm}$, and a length of approximately $1.4 \mu \mathrm{m}$. These data are more accurate than those accused from Deby Scherrer's formula which is usually just estimation from the sizes. By further increasing the temperature to $650{ }^{\circ} \mathrm{C}$ (Figure 2f), length and the concentration of the nanowires were dramatically decreased.

Figure 2. SEM images of the $\mathrm{ZnO}$ nanowires prepared by the oxidation of $\mathrm{Zn}$ thin films in air for $1 \mathrm{~h}$ at temperatures of (a) $450{ }^{\circ} \mathrm{C}$, (b) $500{ }^{\circ} \mathrm{C}$, (c) $550{ }^{\circ} \mathrm{C}$, , d) $600{ }^{\circ} \mathrm{C}$, (f) $650{ }^{\circ} \mathrm{C}$.

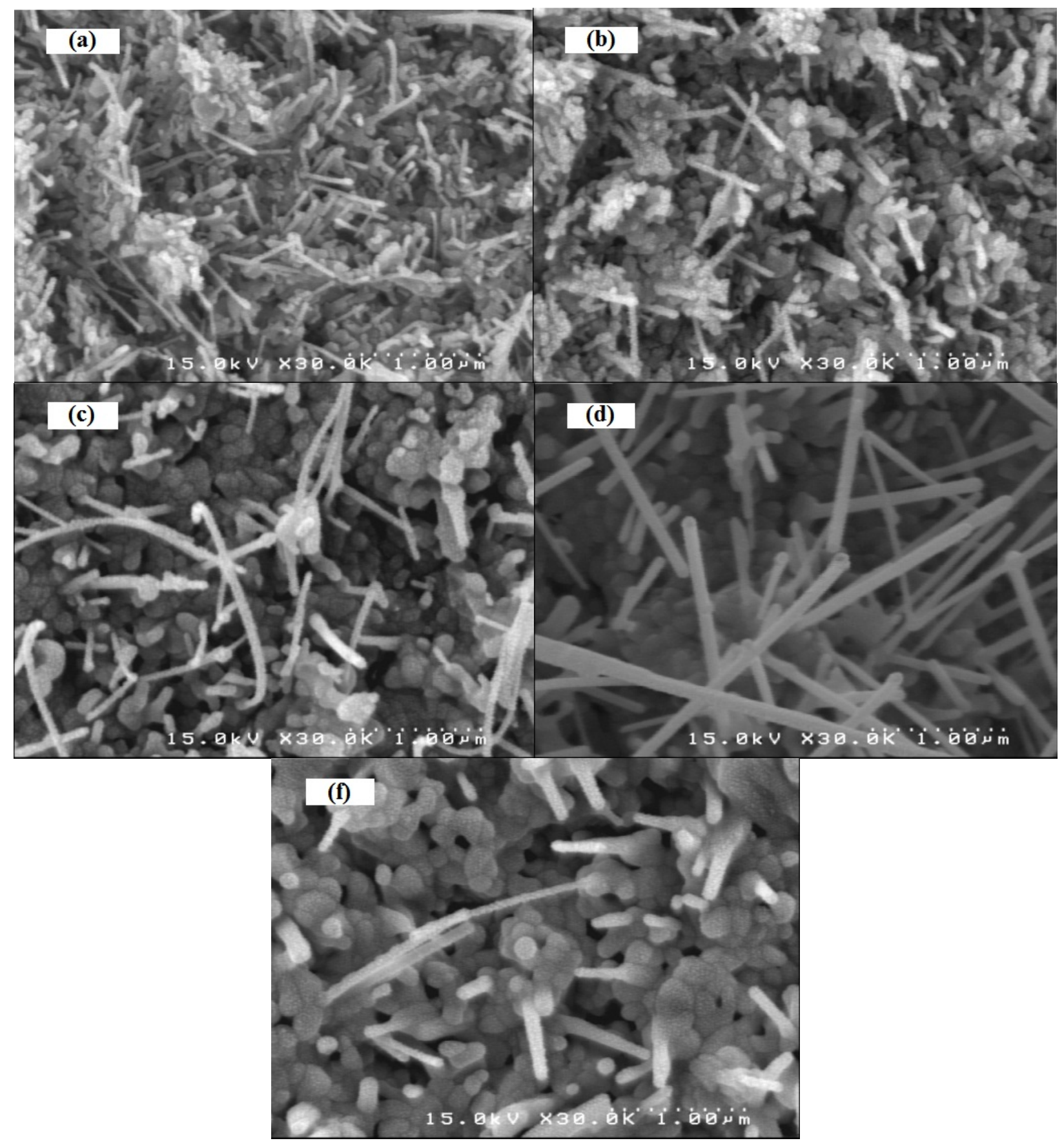

The growth of the 1D nanoforms is generally governed by the catalytic vapor-liquid-solid (VLS) or noncatalytic vapor solid approach. Among the two widely accepted mechanisms for the growth of 1D nanostructures, VLS growth is a catalyst-assisted process, in which a metal catalyst particle acts as a liquid-forming agent [21]. Well-aligned $\mathrm{ZnO}$ nanowires arrays have also been synthesized by catalyst-free 
thermal evaporation methods $[22,23]$. The vapor-solid (VS) mechanism is generally considered to be responsible for the catalyst-free growth of nanowires [24]. It is also proposed that the catalyst-free growth of $\mathrm{ZnO}$ nanowires might include a self-catalyzed vapor-liquid-solid (VLS) process with $\mathrm{Zn}$ or $\mathrm{ZnO}_{\mathrm{x}}$ liquid droplets as catalysts [25]. However, the catalyst-free growth process has not been well understood until now. In the present work, we have prepared $\mathrm{ZnO}$ nanowires without any metal catalyst, therefore the growth mechanism of the nanowires can be explained using the self-catalyzed VLS technique. This mechanism consists of two stages: nucleation and growth [26]. When the oxidation temperature of Zinc thin films was ramped higher than the melting point of metallic $\mathrm{Zn}$ (melting point of $\mathrm{Zn}=419.5^{\circ} \mathrm{C}$ ), the $\mathrm{Zn}$ metal was melted and aggregated to form nano-sized $\mathrm{Zn}$ droplets on the surface of the glass substrate. This liquid $\mathrm{Zn}$ droplet served as catalyst particles, which were the favorable sites for the absorption of $\mathrm{O}_{2}$. The liquid $\mathrm{Zn}$ reacts with oxygen and form nanosized $\mathrm{ZnO}$ nuclei on the surface of the droplets via a simple chemical reaction $2 \mathrm{Zn}$ (l) $+\mathrm{O}_{2} \rightarrow 2 \mathrm{ZnO}$. These $\mathrm{ZnO}$ nuclei individually further grow in the upper direction in the form of nanowires. From the SEM image (Figure 3), we can observe that the individual $\mathrm{Zn}$ grains are oxidized at $600{ }^{\circ} \mathrm{C}$, during a short time of oxidation ( $\sim 30 \mathrm{~min}$ ) that shows nanowires growing from individual $\mathrm{Zn}$ grains. This growth mechanism ensures that the nanowires are grown with low defects.

Figure 3. SEM image for showing nanowires growing from individual $\mathrm{Zn}$ grains (thin film was oxidized at $600{ }^{\circ} \mathrm{C}$ for $30 \mathrm{~min}$ in air).

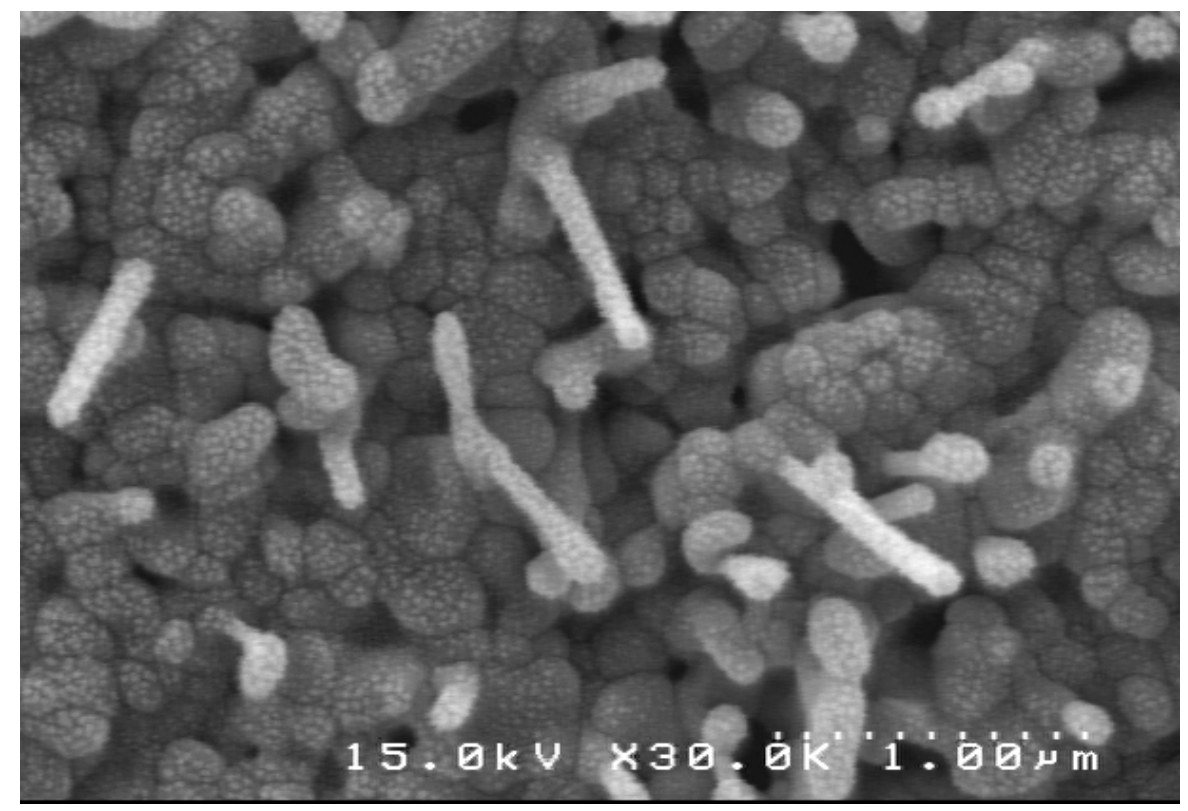

An energy dispersive X-ray (EDX) spectrum of the $\mathrm{ZnO}$ nanowires is shown in Figure 4. Some features of $\mathrm{Zn}$ and $\mathrm{O}$ atoms can only be observed in this spectrum. The appearance of Si peak in the spectrum is due to the substrate. Au peaks are from the gold coating. Detecting just $\mathrm{Zn}$ and O atoms confirms a high purity of the prepared $\mathrm{ZnO}$, although we cannot deny the possible presence of some minor $\mathrm{SiO}_{2}$ impurities which were not detectable in the XRD plot. 
Figure 4. EDX spectrum measured for $\mathrm{ZnO}$ nanowires prepared by the oxidation of $\mathrm{Zn}$ thin films at a temperature of $600{ }^{\circ} \mathrm{C}$.

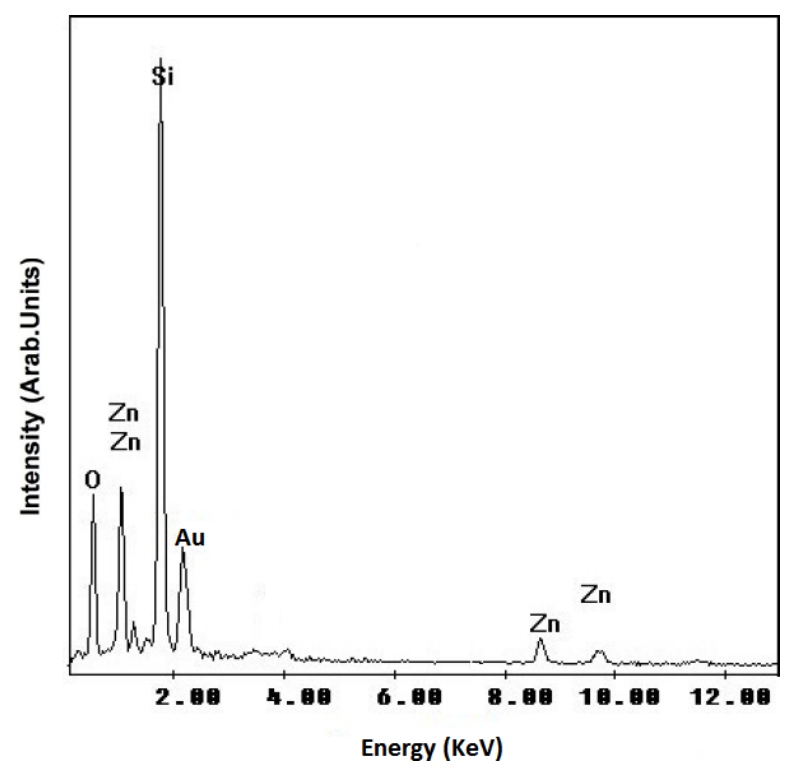

To study the optical properties of $\mathrm{ZnO}$ nanowires, a room temperature photoluminescence (PL) spectrum of a sample prepared at $600{ }^{\circ} \mathrm{C}$ (as an example of the prepared samples) was taken by a Xe light $(325 \mathrm{~nm})$ as the excitation source. The spectrum (Figure 5) is composed of an ultraviolet (UV) emission centered at about $377 \mathrm{~nm}$ and a broad green emission centered at about $522 \mathrm{~nm}$. The UV emission band can be explained by the near band-edge transition of the wide band gap $\mathrm{ZnO}$ nanowires, the recombination of free excitons through an exciton-exciton collision process [27], whereas the peak at $522 \mathrm{~nm}$ is due to the deep-level emission (DLE) related to the defects such as oxygen vacancies and $\mathrm{Zn}$ interstitials $[28,29]$. It has been suggested that the DLE corresponds to the singly ionized oxygen vacancy in $\mathrm{ZnO}$ and results from the recombination of a photo-generated hole with the singly ionized charge state of this defect [30]. Strong UV emission and relatively weak green emission from the $\mathrm{ZnO}$ nanowires confirm that the grown nanowires posses good optical properties with less structural defects and impurities.

Figure 5. Room temperature's $\mathrm{PL}$ spectrum of the $\mathrm{ZnO}$ nanowires prepared by the oxidation of $\mathrm{Zn}$ thin films at $600^{\circ} \mathrm{C}$.

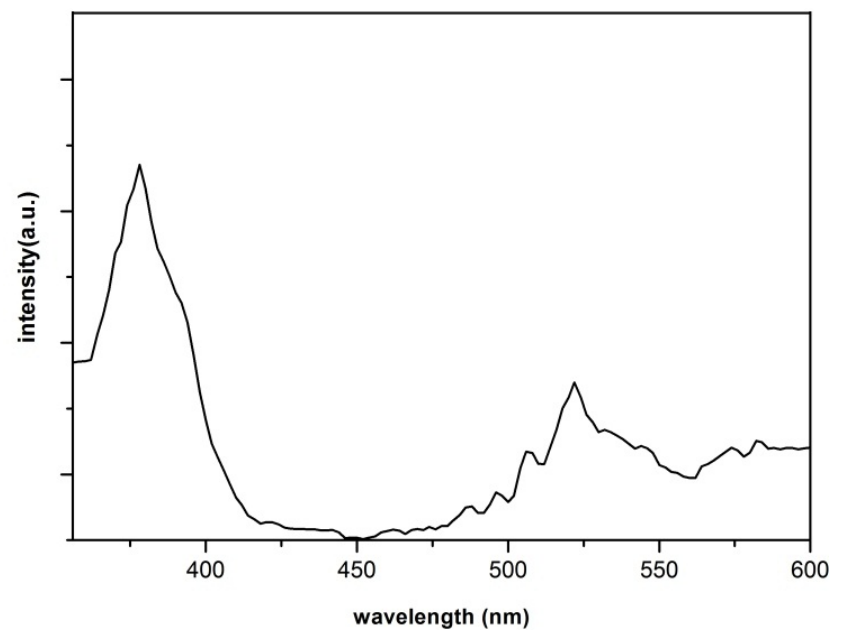




\section{Experimental}

Thin films of metallic zinc were deposited by thermal evaporation under vacuum on glass substrates. The source material was zinc metal granulate (Sigma-Aldrich, St. Louis, MO, USA) with a purity of $99.99 \%$. Pressure of the growth chamber was on the order of $10^{-5}$ Torr. The substrate was kept at room temperature (RT) during the coating process. The distance between the zinc source and the substrate was $20 \mathrm{~cm}$. The $\mathrm{Zn}$ films were prepared with some different thickness of 80, 125, 250 and $500 \mathrm{~nm}$. To synthesize $\mathrm{ZnO}$ nanowires, $\mathrm{Zn}$ films were thermally oxidized in a conventional tube furnace at a temperature of $450-600{ }^{\circ} \mathrm{C}$ in air for $1 \mathrm{~h}$ or less. The crystal structures of the samples were investigated using X-ray diffraction (XRD, Philips Pw 1800, Eindhoven, The Netherlands) technique with $\mathrm{Cuk}_{\alpha}$ radiation $(\lambda=0.154 \mathrm{~nm})$ in the $2 \theta$ range of $20^{\circ}-80^{\circ}$. The surface morphologies and components of the oxidized $\mathrm{Zn}$ films were characterized using a scanning electron microscope (SEM, Hitachi S-4160, Tokyo, Japan) and energy dispersive X-ray (EDX) spectroscope (coupled with the Hitachi S-4160), respectively. The photoluminescence (PL, fluorescence spectrometer, Varian Cary Eclipse, Victoria, Australia) spectra of $\mathrm{ZnO}$ nanowires were taken at $\mathrm{RT}$ using xenon light with a wavelength of $325 \mathrm{~nm}$ as an excitation source.

\section{Conclusions}

High quality zinc oxide nanowires were successfully synthesized on glass substrates by thermal oxidation in air of metallic $\mathrm{Zn}$ thin films at various temperatures between $450{ }^{\circ} \mathrm{C}$ and $650{ }^{\circ} \mathrm{C}$. Actually by annealing at $550{ }^{\circ} \mathrm{C}$ and higher temperatures, all of the $\mathrm{Zn}$ atoms were transformed to $\mathrm{ZnO}$. XRD analysis demonstrated that the $\mathrm{ZnO}$ nanowires has a wurtzite structure with orientation of (002), and the nanowires prepared at $600{ }^{\circ} \mathrm{C}$ has better crystalline quality than samples prepared at other temperatures. SEM results indicated that by increasing the oxidation temperature, the dimension of the $\mathrm{ZnO}$ nanowires increases. The optimum temperature for synthesizing high density $\mathrm{ZnO}$ nanowires was determined to be $600{ }^{\circ} \mathrm{C}$. The growth mechanism of the $\mathrm{ZnO}$ nanowires seems more likely to be explained by a self-catalytic VLS process. Room temperature PL spectra of the ZnO nanowires showed a strong UV emission peak located at around $377 \mathrm{~nm}$ and a relatively weak green emission at around $522 \mathrm{~nm}$, confirming that the as-grown nanowires possess good optical properties.

\section{Acknowledgements}

The authors would like to express their thanks to Imam Khomeini International University for financial support.

\section{References and Notes}

1. Duan, X.F.; Huang, Y.; Cui, Y.; Wang, J.F.; Lieber, C.M. Indium phosphide nanowires as building blocks for nanoscale electronic and optoelectronic devices. Nature 2001, 409, 66-69.

2. Kind, H.; Yan, H.; Law, M.; Messer, B.; Yang, P. Nanowire ultraviolet photodetectors and optical switches. Adv. Mater. 2002, 14, 158-160. 
3. Huang, Y.; Duan, X.; Cui, Y.; Laubon, L.J.; Kim, K.H.; Lieber, C.M. Logic gates and computation from assembled nanowire building blocks. Science 2001, 294, 1313-1317.

4. Wang, X.D.; Zhou, J.; Song, J.H.; Liu, J.; Xu, N.S.; Wang, Z.L. Piezoelectric field effect transistor and nanoforce sensor based on a single $\mathrm{ZnO}$ nanowire. Nano Lett. 2006, 6, 2768-2772.

5. Law, M.; Greene, L.E.; Johnson, J.C.; Saykally, R.; Yang, P.D. Nanowire dye-sensitized solar cell. Nat. Mater 2005, 4, 455-459.

6. Lim, J.H.; Kang, C.K.; Kim, K.K.; Park, I.K.; Hwang, D.K.; Park, S.J. UV electroluminescence emission from $\mathrm{ZnO}$ eight-Emitting diodes grown by high temperature radiofrequency sputtering. Adv. Mater. 2006, 18, 2720-2724.

7. Ikegami, K.; Yoshiyama, T.; Maejima, K.; Shibata, H.; Tampo, H.; Niki, S. Optical dielectric constant inhomogeneity along the growth axis in $\mathrm{ZnO}$-based transparent electrodes deposited on glass substrates. J. Appl. Phys. 2009, 105, 093713-093719.

8. Wan, Q.; Lin, C.L.; Yu, X.B.; Wang, T.H. Room-temperature hydrogen storage characteristics of ZnO nanowires. Appl. Phys. Lett. 2004, 84, 124-126.

9. Zhang, N.; Yi, R.; Shi, R.R.; Gao, G.H.; Chen, G.; Liu, X.H. Novel rose-like ZnO nanoflowers synthesized by chemical vapor deposition. Mater. Lett. 2009, 63, 496-499.

10. Varanasi, C.V.; Leedy, K.D.; Tomich, D.H.; Subramanyam, G.; Look, D.C. Improved photoluminescence of vertically aligned $\mathrm{ZnO}$ nanorods grown on $\mathrm{BaSrTiO}_{3}$ by pulsed laser deposition. Nanotechnology 2009, 20, doi:10.1088/0957-4484/20/38/385706.

11. Ham, H.; Shen, G.; Cho, J.H.; Lee, T.J.; Seo, S.H.; Lee, C.J. Vertically aligned ZnO nanowires produced by a catalyst-free thermal evaporation method and their field emission properties. Chem. Phys. Lett. 2005, 404, 69-73.

12. Wu, J.J.; Liu, S.C. Low-temperature growth of well-aligned $\mathrm{ZnO}$ nanorods by chemical vapor deposition. Adv. Mater. 2002, 14, 215-218.

13. Cho, S.; Ma, J.; Kim, Y.; Sun, Y.; Wong, G.K.L.; Ketterson, J.B. Photoluminescence and ultraviolet lasing of polycrystalline $\mathrm{ZnO}$ thin films prepared by the oxidation of the metallic $\mathrm{Zn}$. Appl. Phys. Lett. 1999, 75, 2761-2763.

14. Zhao, J.; Hu, L.Z.; Wang, Z.Y.; Zhao, Y.; Liang, X.P.; Wang, M.T. High-quality ZnO thin films prepared by low temperature oxidation of metallic Zn. Appl. Surf. Sci. 2004, 229, 311-315.

15. Wang, Y.G.; Lau, S.P.; Lee, H.W.; Yu, S.F.; Tay, B.K.; Zhang, X.H. Photoluminescence study of $\mathrm{ZnO}$ films prepared by thermal oxidation of Zn metallic films in air. J. Appl. Phys. 2003, 94, 354-358.

16. Dang, H.Y.; Wang, J.; Fan, S.S. The synthesis of metal oxide nanowires by directly heating metal samples in appropriate oxygen atmospheres. Nanotechnology 2003, 14, 738-741.

17. Kim, T.W.; Kawazoe, T.; Yamazaki, S.; Ohtsu, M.; Sekiguchi, T. Low-temperature orientationselective growth and ultraviolet emission of single-crystal $\mathrm{ZnO}$ nanowires. Appl. Phys. Lett. 2004, $84,3358-3360$.

18. Srivatsa, K.M.K; Chhikara, D; Kumar, S. Synthesis of aligned ZnO nanorod array on silicon and sapphire substrate bye thermal evaporation technique. J. Mater. Sci. Technol. 2011, 27, 701-706.

19. Dai, L.; Chen, X.L.; Wang, W.J.; Zhou, T.; Hu, B.Q. Growth and luminescence characterization of large-scale zinc oxide nanowires. J. Phys. Condens. Matter 2003, 15, 2221-2226.

20. Cullity, B.D. Elements of X-ray Diffraction; Addison Wesley: Reading, MA, USA, 1978; p. 102. 
21. Umar, A.; Jeong, J.P.; Suh, E.K.; Hahn, Y.B. Synthesis of ZnO nanowires on steel alloy substrate by thermal evaporation: Growth mechanism and structural and optical properties. Korean J. Chem. Eng. 2006, 23, 860-865.

22. Geng, C.Y.; Jiang, Y.; Yao, Y.; Meng, X.M.; Zapien, J.A.; Lee, C.S.; Lifshitz, Y.; Lee, S.T. Well-aligned $\mathrm{ZnO}$ nanowire arrays fabricated on silicon substrates. Adv. Func. Mater. 2004, 14, 589-594.

23. Wang, L.S.; Zhang, X.Z.; Zhao, S.Q.; Zhou, G.Y.; Zhou, Y.L.; Qi, J.J. Synthesis of well-aligned $\mathrm{ZnO}$ nanowires by simple physical vapor deposition on $c$-oriented $\mathrm{ZnO}$ thin films without catalysts or additives. Appl. Phys. Lett. 2005, 86, 024108-024110.

24. Yang, P.; Lieber, C.M. Nanostructured high-temperature superconductors: Creation of strong-pinning columnar defects in nanorod/superconductor composites. J. Mater. Res. 1997, 12, 2981-2996.

25. Kar, S.; Pal, B.N.; Chaudhuri, S.; Chakravorty, D. One-dimensional ZnO nanostructure arrays: Synthesis and characterization J. Phys. Chem. B 2006, 110, 4605-4611.

26. Kim, S.H.; Umar, A.; Hahn, Y.B. Growth and formation mechanism of sea urchin-like $\mathrm{ZnO}$ nanostructures on Si. Korean J. Chem. Eng. 2005, 22, 489-493.

27. Kong, Y.C.; Yu, D.P.; Zhang, B.; Fang, W.; Feng, S.Q. Ultraviolet-emitting ZnO nanowires synthesized by a physical vapor deposition approach. Appl. Phys. Lett. 2001, 78, 407-409.

28. Lin, C.C.; Liu, K.H.; Chen, S.Y. Growth and characterization of Zn-ZnO core-shell polygon prismatic nanocrystal on Si. J. Cryst. Growth 2004, 269, 425-431.

29. Xu, L.F.; Guo, Y.; Liao, Q.; Zhang, J.P.; Xu, L.S. Morphological control of ZnO nanostructures by electrodeposition. J. Phys. Chem. B 2005, 109, 13519-13522.

30. Vanheusden, K.; Warren, W.L.; Seager, C.H.; Tallant, D.R.; Voigt, J.A.; Gnade, B.E. Mechanisms behind green photoluminescence in $\mathrm{ZnO}$ phosphor powders. J. Appl. Phys. 1996, 79, 7983-7990.

Sample Availability: Samples of the compounds $\mathrm{ZnO}$ nanowires are available from the authors.

(C) 2012 by the authors; licensee MDPI, Basel, Switzerland. This article is an open access article distributed under the terms and conditions of the Creative Commons Attribution license (http://creativecommons.org/licenses/by/3.0/). 